\title{
Biosynthesis of Quinolactacin A, a TNF Production Inhibitor
}

\author{
Tatsuya Sasaki, Senji Takahashi, Kenichi Uchida, Shinji Funayama, \\ Masatsune Kainosho, Akira Nakagawa
}

Received: February 24, 2006 / Accepted: July 19, 2006

(C) Japan Antibiotics Research Association

\begin{abstract}
Quinolactacins, which inhibit tumor necrosis factor production, contain a quinolone skeleton conjugated with a $\gamma$-lactam. The biosynthesis of quinolactacin was investigated by feeding experiments using ${ }^{13} \mathrm{C}$ singlelabeled precursors (sodium $\left[1-{ }^{13} \mathrm{C}\right]$ acetate, DL- $\left[1-{ }^{13} \mathrm{C}\right]-$ isoleucine, $\mathrm{L}-\left[\right.$ methyl $\left.-{ }^{13} \mathrm{C}\right]$ methionine, and sodium $\left[1-{ }^{13} \mathrm{C}\right]-$ anthranilate) and $\mathrm{D}-\left[U-{ }^{13} \mathrm{C}\right]$ glucose.
\end{abstract}

Keywords quinolactacin, quinolone, biosynthesis, ${ }^{13} \mathrm{C}$ labeled precursor, Penicillium sp.

\section{Introduction}

Since entomopathogenic fungi possess a parasitic function, it was expected that novel biologically active compounds such as insecticides and immunosuppressants would be isolated from them [1 7]. In the course of an HPLC-based, chemical screening program of the metabolites of entomopathogenic fungi, the novel pyridone alkaloids, pyridovericin and pyridomacrolidin, possessing protein kinase inhibitory activity, were isolated from the cultured broth of Beauveria bassiana EPF-5 [8, 9]. In addition, novel quinolone alkaloids, quinolactacins A (1), B (2), and C (3) were obtained from the cultured broth of Penicillium sp. EPF-6, which was isolated from the larvae of the mulberry pyralid (Margaronia pyloalis Welker) [10]. Alkaloid 1, the major constituent, exhibited inhibitory activity against tumor necrosis factor (TNF) production by murine macrophages and macrophage-like J774.1 cells stimulated with lipopolysaccharide (LPS).

Quinolactacins have a unique quinolone skeleton conjugated with a $\gamma$-lactam ring [11], as shown in Figure 1. Subsequently, Kim et al., reported the characterization of stereoisomers of $\mathbf{1}$ through a screening program for inhibitors of acetylcholinesterase [12], and Tatsuta's group reported the biomimetic synthesis of quinolactacin B (2) using acetic acid, valine, and anthranilic acid [13]. In this paper, the biosynthesis of $\mathbf{1}$ was studied by feeding experiments using several ${ }^{13} \mathrm{C}$ single-labeled precursors and D- $\left[U_{-}{ }^{13} \mathrm{C}\right]$ glucose.

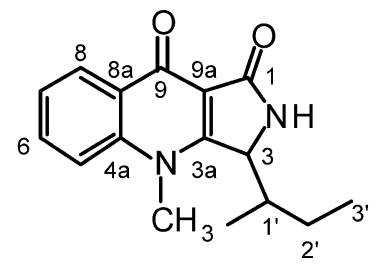

1<smiles>CC(C)C1NC(=O)c2c1n(C)c1ccccc1c2=O</smiles>

2<smiles>CCC(C)C1(O)NC(=O)c2c1n(C)c1ccccc1c2=O</smiles>

3
Fig. 1 Structures of quinolactacins A (1), B (2), and C (3).
A. Nakagawa (Corresponding author), T. Sasaki, S. Takahashi, K. Uchida: Department of Biosciences, Teikyo University, 1-1 Toyosatodai, Utsunomiya, Tochigi 320-8551, Japan,

E-mail: nakagawa@nasu.bio.teikyo-u.ac.jp
S. Funayama: Department of Kampo Pharmaceutical Sciences, Nihon Pharmaceutical University, 10281 Ina-machi Komuro, Saitama 362-0806, Japan

M. Kainosho: Graduate School of Science, Tokyo Metropolitan University, 1-1 Minami-ohsawa, Hachioji, Tokyo 192-0397, Japan 


\section{Materials and Methods}

\section{Microorganism}

Penicillium sp. EPF-6 [10] was used for the biosynthetic studies of quinolactacin A (1).

\section{${ }^{13}$ C Labeled Precursors}

Sodium $\left[1-{ }^{13} \mathrm{C}\right]$ acetate $\left(99 \%{ }^{13} \mathrm{C}\right.$ enriched $)$, DL- $\left[1-{ }^{13} \mathrm{C}\right]-$ isoleucine $\left(99 \%{ }^{13} \mathrm{C}\right.$ enriched), and $\mathrm{L}-\left[\right.$ methyl $\left.-{ }^{13} \mathrm{C}\right]-$ methionine $\left(99 \%{ }^{13} \mathrm{C}\right.$ enriched) were purchased from ISOTEC Inc., USA. D- $\left[U_{-}{ }^{13} \mathrm{C}\right]$ Glucose $\left(99 \%{ }^{13} \mathrm{C}\right.$ enriched) was purchased from Shoko Co. Ltd. (Tokyo). Sodium [1${ }^{13} \mathrm{C}$ ]anthranilate $\left(99 \%{ }^{13} \mathrm{C}\right.$ enriched) was prepared from sodium $\left[{ }^{13} \mathrm{C}\right]$ cyanide $\left(99 \%{ }^{13} \mathrm{C}\right.$ enriched) as described below.

\section{Copper (I) $\left[{ }^{13} \mathrm{C}\right]$ Cyanide}

A solution of $1.5 \mathrm{~g}$ of sodium bisulfite in $4 \mathrm{ml}$ of water warmed at $50^{\circ} \mathrm{C}$, was added to a solution of $5.0 \mathrm{~g}$ of copper(II) sulfate pentahydrate in $14 \mathrm{ml}$ of water at $50^{\circ} \mathrm{C}$. Immediately, the solution of $1.5 \mathrm{~g}$ of potassium $\left[{ }^{13} \mathrm{C}\right]$ cyanide $\left(99 \%{ }^{13} \mathrm{C}\right.$ enriched, ISOTEC Inc., USA) in $3 \mathrm{ml}$ of water was added to the resulting dark brownish solution below $80^{\circ} \mathrm{C}$. After 10 minutes stirring the white precipitate was filtered off, and washed with hot water, cold water and $\mathrm{EtOH}$, successively. The product was dried over $\mathrm{P}_{4} \mathrm{O}_{10}$ in vacuo. Yield: $1.25 \mathrm{~g}(91 \%)$.

\section{[1- $\left.{ }^{13} \mathbf{C}\right]$ 2-Nitrobenzonitrile $[14,15]$}

A mixture of $3.4 \mathrm{~g}$ of 2-bromonitrobenzene, $1.25 \mathrm{~g}$ of $\mathrm{Cu}^{13} \mathrm{CN}$ and $1.33 \mathrm{~g}$ of pyridine was heated at $140^{\circ} \mathrm{C}$ on an oil bath for 3 hours. After cooling to room temperature, the solidified reaction mixture was well grained and dissolved in three portions of the mixture of conc. aqueous ammonia and ether $(100 \mathrm{ml}+50 \mathrm{ml})$. The extracts were combined and the insoluble materials were removed by suction with a glass filter. The ether layer was separated, and the aqueous solution was extracted with three portions of ether. All ether layers were combined, and then washed successively with $1 \mathrm{M} \mathrm{NH}_{4} \mathrm{OH}, 1 \mathrm{M} \mathrm{HCl}$, and water. The solution was dried over anhydrous sodium sulfate, and then the solvent was removed. The obtained brownish product was used for the following reaction without further purification. Yield: $2.6 \mathrm{~g}$ (quantitative).

\section{$\left[1-{ }^{13} \mathrm{C}\right]$ 2-Nitrobenzoic Acid}

A solution of $2.6 \mathrm{~g}$ of $\left[1-{ }^{13} \mathrm{C}\right] 2$-nitrobenzonitrile in a mixture of conc. $\mathrm{HBr}$ and glacial acetic acid $(80 \mathrm{ml}+20 \mathrm{ml})$ was refluxed for 16 hours. The reaction mixture was evaporated to dryness, and the residue was redissolved in
$20 \mathrm{ml}$ of $1 \mathrm{M} \mathrm{NaOH}$ solution. The solution was washed with ether and acidified up to $\mathrm{pH} 1$ with $6 \mathrm{M} \mathrm{HCl}$, followed by extraction with three portions of ether. The ether layers were combined and washed with water and dried over anhydrous sodium sulfate. The solvent was evaporated, and the product was obtained with the yield of $2.0 \mathrm{~g}$ ( $86 \%$ from $\mathrm{Cu}^{13} \mathrm{CN}$ ). This product was used for the next reaction without further purification.

\section{$\left[1-{ }^{13} \mathrm{C}\right]$ Anthranilic Acid}

A mixture of $2.0 \mathrm{~g}$ of $\left[1-{ }^{13} \mathrm{C}\right]$ 2-nitrobenzoic acid, $0.15 \mathrm{~g}$ of $10 \% \mathrm{Pd} /$ carbon, and $3.8 \mathrm{~g}$ of ammonium formate in $30 \mathrm{ml}$ of $\mathrm{MeOH}$ was stirred for 1 hour at room temperature. After removing catalyst by suction, solvent was evaporated. The residue was dissolved in $30 \mathrm{ml}$ of $10 \% \mathrm{MeOH}$ in water, and the obtained solution was applied to a Dowex-50X8 column $\left(\mathrm{H}^{+}\right.$form, $\left.2.5 \times 15 \mathrm{~cm}\right)$. The product was eluted with the mixed solvent of conc. aqueous ammonia, $\mathrm{MeOH}$, and water $(1: 1: 8)$. The active fractions were collected and the solvent was evaporated. The further purification for decolorization was carried out by silica gel column chromatography $(3 \times 5 \mathrm{~cm})$ eluted with the mixed solvent of $\mathrm{CHCl}_{3}$ and $\mathrm{MeOH}(10: 1)$. The labeled anthranilic acid was obtained by the yield of $1.53 \mathrm{~g}\left(80 \%\right.$ from $\left.\mathrm{Cu}^{13} \mathrm{CN}\right)$. MP $144.7 \sim 145.3^{\circ} \mathrm{C}$.

\section{Fermentation of the Quinolactacin-producing Strain, Penicillium sp. EPF-6}

For the biosynthetic studies, the production of 1 was examined using several modifications of liquid and solid media. As a result, a SC-1 solid medium consisting of brown rice $(30 \%)$, yeast extract $(0.07 \%)$, sodium tartrate $(0.03 \%)$, and $\mathrm{K}_{2} \mathrm{HPO}_{4}(0.03 \%)$ was found to be the most suitable medium for the selective production of $\mathbf{1}$. The production of 1 was as high as $6.4 \mathrm{mg} / 100 \mathrm{ml}$. On the other hand, the production of alkaloid $\mathbf{1}$ was extremely low, or $\mathbf{1}$ was not produced, in the liquid media generally used for the fermentation of fungi. Thus, the biosynthetic studies of 1 were carried out using the SC-1 solid medium.

Penicillium sp. EPF-6 was cultured in an Erlenmeyer flask $(500 \mathrm{ml})$ containing a liquid medium $(100 \mathrm{ml})$ (glucose $1.0 \%$, potato starch $2.0 \%$, polypeptone $0.5 \%$, yeast extract $0.5 \%, \mathrm{CaCO}_{3} 0.4 \%, \mathrm{pH} 7.0$ ) for 4 days at $28^{\circ} \mathrm{C}$ on a rotary shaker at $200 \mathrm{rpm}$. The seed culture $(6 \%)$ was inoculated into each flask containing the solid medium $(100 \mathrm{ml})$ as described above. Penicillium sp. EPF-6 using SC-1 solid medium was cultivated for 17 days at $28^{\circ} \mathrm{C}$ under stationary conditions. 


\section{Feeding Experiments of ${ }^{13} \mathrm{C}$ Labeled Precursors and the Isolation of ${ }^{13} \mathrm{C}$ Enriched 1}

The biosynthetic origin of the carbon skeleton in 1 was examined by feeding experiments using ${ }^{13} \mathrm{C}$ enriched precursors, i.e. sodium $\left[1-{ }^{13} \mathrm{C}\right]$ acetate $(0.3 \% \mathrm{w} / \mathrm{v})$, DL- $[1-$ $\left.{ }^{13} \mathrm{C}\right]$ isoleucine $(0.2 \% \mathrm{w} / \mathrm{v})$, L- $\left[\right.$ methyl $\left.-{ }^{13} \mathrm{C}\right]$ methionine $(0.2 \%$ $\mathrm{w} / \mathrm{v})$, sodium $\left[1-{ }^{13} \mathrm{C}\right]$ anthranilate $(0.25 \% \mathrm{w} / \mathrm{v})$, and $99 \% \mathrm{D}-$ $\left[U_{-}{ }^{13} \mathrm{C}\right]$ glucose $(3 \% \mathrm{w} / \mathrm{v})$, respectively. Each ${ }^{13} \mathrm{C}$-enriched precursor was fed to a 5 day-old culture of Penicillium sp. EPF-6, and the fermentation was continued for another 12 days.

Quinolactacin A (1) enriched by the respective ${ }^{13} \mathrm{C}$ labeled precursor was isolated as a white powder from each cultured broth $(300 \sim 500 \mathrm{ml})$ using Diaion HP-20 (solvent: $\mathrm{H}_{2} \mathrm{O}$-acetone) and silica gel column chromatography (solvent: $\mathrm{CHCl}_{3}-\mathrm{MeOH}$ ), followed by Sephadex LH-20 column chromatography (solvent: $\mathrm{MeOH}$ ). Finally, each ${ }^{13} \mathrm{C}$ enriched sample of $\mathbf{1}(2 \sim 5 \mathrm{mg})$ was isolated by preparative HPLC under the following conditions: column; Supelcosil $\mathrm{ABZ}+$ plus $4.6 \mathrm{~mm} \times 250 \mathrm{~mm}$ (mobile phase: acetonitrile : $\mathrm{H}_{2} \mathrm{O}=20: 80$ ); UV detection at $210 \mathrm{~nm}$; flow rate of $0.7 \mathrm{ml} /$ minute. Alkaloid 1 was eluted with a retention time of 15.1 minutes. The ${ }^{13} \mathrm{C}$ NMR $(125 \mathrm{MHz})$ spectra of each sample of ${ }^{13} \mathrm{C}$ labeled $\mathbf{1}$ was acquired in DMSO- $d_{6}$ at $30^{\circ} \mathrm{C}$ (Table 2).

\section{NMR Measurements}

The NMR spectra for the determination of the enrichment factors with single labeled precursors were recorded on an EX-400 (JEOL) spectrometer at $30^{\circ} \mathrm{C}$. For the measurement of the sample of 1 obtained by feeding D-[ $U$ ${ }^{13} \mathrm{C}$ ]glucose, the NMR spectra were recorded on a DRX600 (Burker) spectrometer at $30^{\circ} \mathrm{C}$ using the parameters as described below. The ${ }^{1} \mathrm{H}$ NMR spectra were recorded by using $7.8 \mu$ seconds of observed pulse ( $45^{\circ}$ pulse) and 1.51 seconds of reputation cycle. The ${ }^{13} \mathrm{C}$ NMR spectra were obtained with the pulse width of $6.0 \mu$ seconds $\left(30^{\circ}\right.$ pulse $)$ and 1.44 seconds reputation cycle under full proton decoupling. All the samples of isotopically labeled 1 were dissolved in DMSO- $d_{6}$. The chemical shift values of ${ }^{1} \mathrm{H}$ and ${ }^{13} \mathrm{C}$ NMR signals were measured using DMSO signals by the conversion factors as $2.54 \mathrm{ppm}$ for the ${ }^{1} \mathrm{H}$ NMR signals and $39.50 \mathrm{ppm}$ for the ${ }^{13} \mathrm{C}$ NMR signals, respectively.

\section{Estimation of ${ }^{13} \mathrm{C}$ Signal Intensity Ratio of Satellite Signals in the Case of Randomly Labeled Three-Spin System}

We assume a model case of continuous three-spin system as $s_{1}-S_{2}-S_{3}$. When concentrations of ${ }^{13} \mathrm{C}$ of each site are defined as $c_{1}, c_{2}$ and $c_{3},{ }^{12} \mathrm{C}$ concentrations are given by $\left(1-c_{1}\right),\left(1-c_{2}\right)$ and $\left(1-c_{3}\right)$, respectively. If distribution of ${ }^{13} \mathrm{C}$ atoms proposes to be random, all of the labeling patterns of each site are represented as shown in Table 1. Since the ${ }^{13} \mathrm{C}$ NMR signal is observed only when the carbon is ${ }^{13} \mathrm{C}$ at this site, the signal intensity of $s_{2}$ carbon which is observed as singlet is calculated by

$$
\text { singlet: }\left(1-c_{1}\right) c_{2}\left(1-c_{3}\right)
$$

Similarly each intensity of doublet and double doublet at $s_{2}$ site are given as follows,

$$
\begin{aligned}
& \text { doublet: } c_{1} c_{2}\left(1-c_{3}\right)+\left(1-c_{1}\right) c_{2} c_{3} \\
& \text { double doublet: } c_{1} c_{2} c_{3}
\end{aligned}
$$

Therefore, the signal intensity ratio is given by

singlet : doublet : double doublet $=$

$$
\left(1-c_{1}\right)\left(1-c_{3}\right):\left\{c_{1}\left(1-c_{3}\right)+\left(1-c_{1}\right) c_{3}\right\}: c_{1} c_{3}
$$

Table 1 The distribution patterns of ${ }^{13} \mathrm{C}$ and ${ }^{12} \mathrm{C}$ atoms on a continuous three-spin system, $s_{1}-s_{2}-s_{3}$

\begin{tabular}{ccccc}
\hline & \multicolumn{3}{c}{${ }^{13} \mathrm{C}$ and ${ }^{12} \mathrm{C}$ concentrations of each site } & \\
\cline { 2 - 4 } & $s_{1}$ & $s_{2}$ & $s_{3}$ & Remarks $^{a}$ \\
\hline 1 & $1-c_{1}$ & $1-c_{2}$ & $1-c_{3}$ & - \\
2 & $c_{1}$ & $1-c_{2}$ & $1-c_{3}$ & \\
3 & $1-c_{1}$ & $c_{2}$ & $1-c_{3}$ & $s_{2}$ is observed as singlet \\
4 & $1-c_{1}$ & $1-c_{2}$ & $c_{3}$ & - \\
5 & $c_{1}$ & $c_{2}$ & $1-c_{3}$ & $s_{2}$ is observed as doublet \\
6 & $c_{1}$ & $1-c_{2}$ & $c_{3}$ & \\
7 & $1-c_{1}$ & $c_{2}$ & $c_{3}$ & $s_{2}$ is observed as doublet \\
8 & $c_{1}$ & $c_{2}$ & $c_{3}$ & $s_{2}$ is observed as double doublet \\
\hline
\end{tabular}

${ }^{a}$ The dashes are indicated that no ${ }^{13} \mathrm{C}$ NMR signal is observed at $s_{2}$. 
Table $2{ }^{13} \mathrm{C}$ NMR chemical shifts and ${ }^{13} \mathrm{C}$ enrichment ratios of quinolactacin $\mathrm{A}$

\begin{tabular}{|c|c|c|c|c|c|}
\hline \multirow[b]{2}{*}{ Position } & \multirow{2}{*}{$\begin{array}{c}\delta^{b} \\
(\mathrm{ppm})\end{array}$} & \multicolumn{4}{|c|}{${ }^{13} \mathrm{C}$ Enrichment ratios ${ }^{a}$} \\
\hline & & $\begin{array}{c}\text { Sodium }\left[1-{ }^{13} \mathrm{C}\right] \\
\text { acetate }\end{array}$ & $\begin{array}{l}\mathrm{DL}-\left[1-{ }^{13} \mathrm{C}\right] \\
\text { Isoleucine }\end{array}$ & $\begin{array}{c}\mathrm{L}-\left[\text { methyl- }{ }^{13} \mathrm{C}\right] \\
\text { Methionine }\end{array}$ & $\begin{array}{c}\text { Sodium }\left[1-{ }^{13} \mathrm{C}\right] \\
\text { anthranilate }\end{array}$ \\
\hline 1 & 168.3 & 2.6 & 1.0 & 1.2 & 1.5 \\
\hline 3 & 58.9 & 1.7 & 1.0 & 1.0 & 1.0 \\
\hline За & 164.0 & 2.7 & 7.9 & 1.1 & 1.5 \\
\hline $4 \mathrm{~N}-\mathrm{Me}$ & 36.0 & 1.0 & 0.9 & 18.6 & 1.0 \\
\hline $4 a$ & 141.2 & 3.2 & 1.1 & 1.3 & 1.8 \\
\hline 5 & 117.0 & 2.2 & 1.0 & 1.1 & 1.8 \\
\hline 6 & 132.4 & 2.1 & 1.0 & 1.1 & 1.3 \\
\hline 7 & 124.2 & 2.3 & 1.0 & 1.0 & 1.1 \\
\hline 8 & 125.8 & 2.3 & 1.0 & 1.1 & 1.1 \\
\hline $8 a$ & 128.0 & 2.4 & 0.9 & 1.1 & 1.1 \\
\hline 9 & 171.5 & 2.8 & 1.0 & 1.2 & 1.4 \\
\hline $9 a$ & 110.3 & 2.5 & 1.3 & 2.9 & 2.1 \\
\hline $1^{\prime}$ & 35.7 & 3.2 & 1.0 & 2.7 & 0.5 \\
\hline $1^{\prime}-\mathrm{Me}$ & 17.5 & 0.6 & 1.0 & 1.0 & 0.8 \\
\hline $2^{\prime}$ & 20.8 & 1.0 & 1.0 & 1.1 & 1.0 \\
\hline $3^{\prime}$ & 11.4 & 3.8 & 1.4 & 1.2 & 1.0 \\
\hline
\end{tabular}

\footnotetext{
${ }^{a}$ The ${ }^{13} \mathrm{C}$ enrichment ratios of the signals of labeled $\mathbf{1}$, which was prepared from sodium $\left[1-{ }^{13} \mathrm{C}\right]$ acetate as precursor, was calculated on the basis of the relative intensity of $4 \mathrm{~N}$-Me signal as to be 1.0. In other cases, the enrichment ratios were obtained based on the relative intensities of $\mathrm{C}-3$ signals of individual ${ }^{13} \mathrm{C}$ NMR spectrum.

${ }^{b}$ Measured in DMSO- $d_{6}$ at $30^{\circ} \mathrm{C}$.
}

The same discussion could be applied to the case of fourspin systems.

\section{Results and Discussion}

\section{Incorporation of Single Labeled Precursors to Quinolactacin A}

Biosynthetic origin of each carbon of $\mathbf{1}$ was investigated by ${ }^{13} \mathrm{C}$ NMR analyses of ${ }^{13} \mathrm{C}$ enriched $\mathbf{1}$ which were obtained from the cultured broth of Penicillium sp. EPF-6 by feeding experiments of ${ }^{13} \mathrm{C}$ labeled precursors. The results of the experiments from the feeding of the precursors are summarized in Table 2. Enrichment ratios of sodium $\left[1-{ }^{13} \mathrm{C}\right]$ acetate were determined relative to the intensity of the $N$-methyl signal as 1.0. Enrichments (low level) from sodium $\left[1-{ }^{13} \mathrm{C}\right]$ acetate was observed at the $\mathrm{C}-1, \mathrm{C}-3, \mathrm{C}-3 \mathrm{a}$, C-4a, C-5, C-6, C-7, C-8, C-8a, C-9, C-9a, C-1', and C-3' carbons of $\mathbf{1}$. The labeling pattern demonstrates that acetate is incorporated after metabolism via the Krebs cycle; apparently at rate that is much faster than it is carboxylated to malonyl-CoA, resulting in the extensive scrambling of $\left[1-{ }^{13} \mathrm{C}\right]$ acetate. These results imply that the quinolone skeleton of quinolactacins is not derived from the polyketide pathway, but is synthesized through the shikimate pathway.

In the feeding experiments with DL- $\left[1-{ }^{13} \mathrm{C}\right]$ isoleucine and $\mathrm{L}-\left[\right.$ methyl $\left.-{ }^{13} \mathrm{C}\right]$ methionine, enrichment ratios in $\mathbf{1}$ were measured relative to the intensity of the $\mathrm{C}-3^{\prime}$ signal as 1.0. These results provided unequivocal evidence that the $\mathrm{C}_{6}$ segment (C-3, C-3a, C-1', C-1'-Me, C-2', and C-3') of $\mathbf{1}$ is derived from isoleucine, and that the $N$-methyl group is derived from methionine.

The origin of the $\mathrm{C}_{7} \mathrm{~N}$ unit in $\mathbf{1}$ was considered to be derived from anthranilic acid via the shikimate pathway from the structural features. However, feeding sodium [1${ }^{13} \mathrm{C}$ ]anthranilate afforded no incorporation into the C-9 of 1. Two possibilities may be considered for the lack of incorporation; one is that $\mathrm{C}-\mathbf{9}$ of $\mathbf{1}$ is not derived from anthranilate, and another possibility is that a permeability barrier for anthranilate exists in Penicillium sp. EPF-6. In order to clarifying the biosynthetic pathway of quinolactacin $\mathrm{A}$ in detail, we tried to use of $\mathrm{D}-\left[U_{-}{ }^{13} \mathrm{C}\right]$ glucose as a carbon source.

\section{Incorporation of $\mathrm{D}-\left[\boldsymbol{U}{ }^{13} \mathrm{C}\right] \mathrm{Glucose}$ to Quinolactacin $\mathrm{A}$}

Feeding experiments using D- $\left[U_{-}{ }^{13} \mathrm{C}\right]$ glucose were provided 
valuable information concerning the biosynthetic origin of carbon atoms, and the ${ }^{13} \mathrm{C}$ distribution which reflects on the biosynthetic processes of microbial secondary metabolites [16 18]. Because Penicillium sp. EPF-6 was cultivated using a nutritive rich media containing brown rice, it was worried about the low incorporation rate of $\mathrm{D}-\left[U_{-}{ }^{13} \mathrm{C}\right]-$ glucose to 1 , however, the ${ }^{13} \mathrm{C}$ abundances of obtained labeled $\mathbf{1}$ was actually relatively high. The ${ }^{13} \mathrm{C}$ abundances of each carbon in $\mathbf{1}$ following the incorporation of $\mathrm{D}-[U$ ${ }^{13} \mathrm{C}$ ]glucose were estimated by the integration of the ${ }^{1} \mathrm{H}$ NMR satellite signals caused by the existence of ${ }^{13} \mathrm{C}$ heteronuclear coupling in each proton signal. It was found that the carbon atoms of labeled 1 contain $9 \%$ to $30 \%$ of ${ }^{13} \mathrm{C}$ isotope. With respect to the ${ }^{13} \mathrm{C}$ abundances at $\mathrm{C}-5$ and $\mathrm{C}-6$, their corresponding ${ }^{1} \mathrm{H}$ NMR signals have very close chemical shifts, and thus the ${ }^{13} \mathrm{C}$ enrichments were calculated as the mean of the two sites. The results were shown in Table 2.

In the ${ }^{13} \mathrm{C}$ NMR spectrum of 1 labeled by $\mathrm{D}-\left[U_{-}{ }^{13} \mathrm{C}\right]-$ glucose, ${ }^{13} \mathrm{C}$ signals derived from different isotopomers were observed overlapped each other with a small isotope shift arising from adjacent ${ }^{13} \mathrm{C}$ atoms. As shown in Figs. 3 and 4 , these signals appeared as singlet, doublet, and double doublet, respectively. The ratios of the signal intensity are summarized in Table 3. The singlet signal indicates that it has no neighboring ${ }^{13} \mathrm{C}$ carbon atom. The appearance of doublet and double doublet signals means that one and two ${ }^{13} \mathrm{C}$ atoms were adjacent to the carbon, respectively. The ratio of the integration for these signals is directly proportional to that of the presence of each type of isotopomer, assuming the influences on the relaxation time due to the adjacent ${ }^{13} \mathrm{C}$ atoms is the same. The ${ }^{13} \mathrm{C}-{ }^{13} \mathrm{C}$ spin-spin coupling constants of each signal are also shown in Table 3. By analyzing these distribution patterns of ${ }^{13} \mathrm{C}$ atoms, we could be determined the biosynthetic pathway of $\mathbf{1}$ in detail as follows. The proposal biosynthetic route of $\mathbf{1}$ is shown in Fig. 2.

Figure 3 shows the expanded ${ }^{13} \mathrm{C}$ NMR signals of the $\mathrm{C}$ 1, C-9a, C-3a, C-3, C-1' $, \mathrm{C}-2^{\prime}, \mathrm{C}-1^{\prime}-\mathrm{Me}$, and C-3' carbons of 1 obtained by the feeding of $\mathrm{D}-\left[U_{-}{ }^{13} \mathrm{C}\right]$ glucose. The signal of C-3 was observed as overlapping from three kinds of isotopomers as a singlet, a doublet, and a double doublet. The doublet and double doublet signals were derived from the spin-spin coupling to the neighboring ${ }^{13} \mathrm{C}$ atoms at $\mathrm{C}-1$ and $\mathrm{C}-3 \mathrm{a}$. The concentration of ${ }^{13} \mathrm{C}$ at $\mathrm{C}-3$ was determined as $12 \%$ by the ${ }^{1} \mathrm{H}$ NMR spectrum. The signal intensity ratio of singlet: doublet: double doublet at C-3 carbon should be $70: 27: 3$ (see Material and Methods), if the C-3, C-3a, and
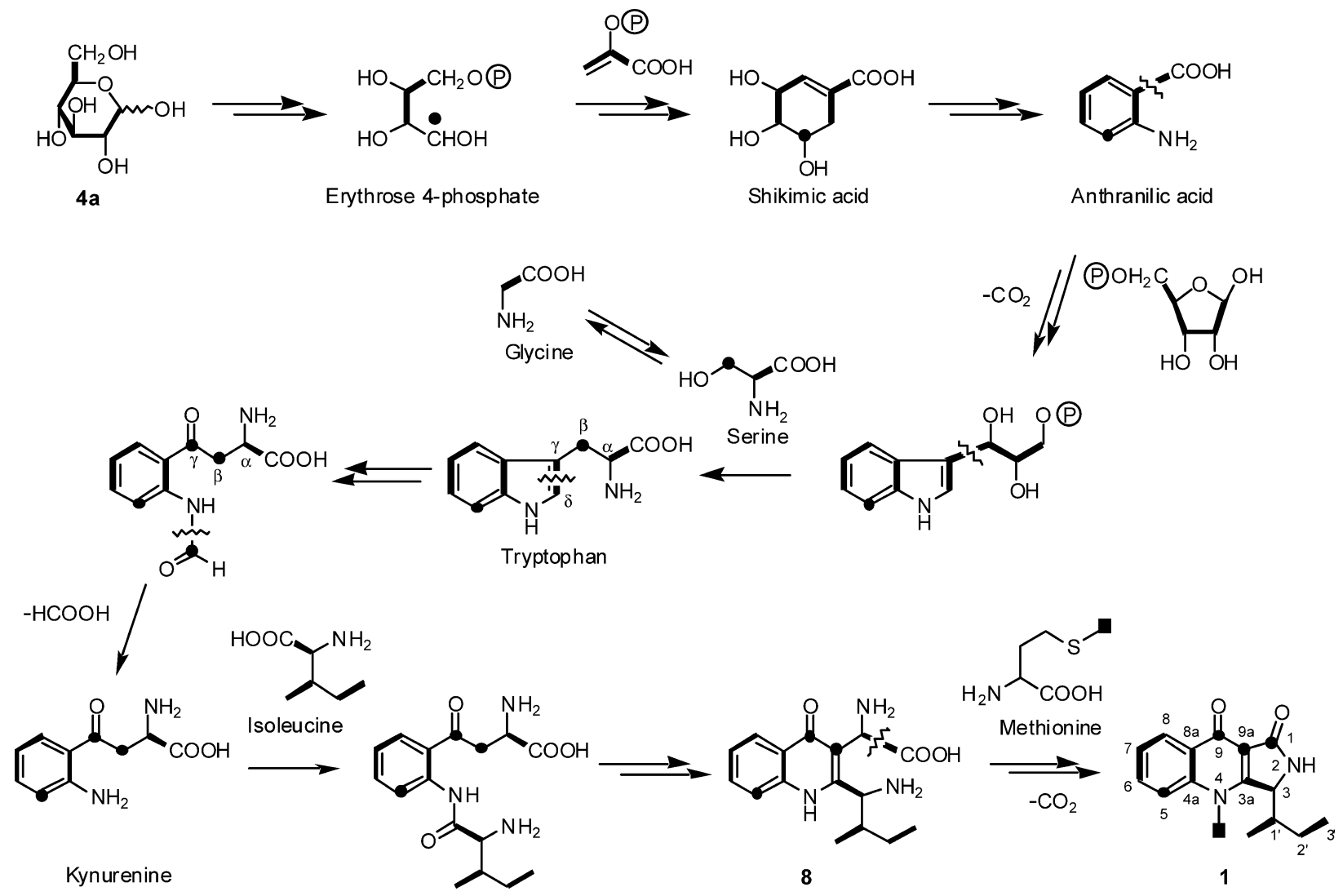

Fig. 2 Biosynthetic pathway of $\mathbf{1}$. 


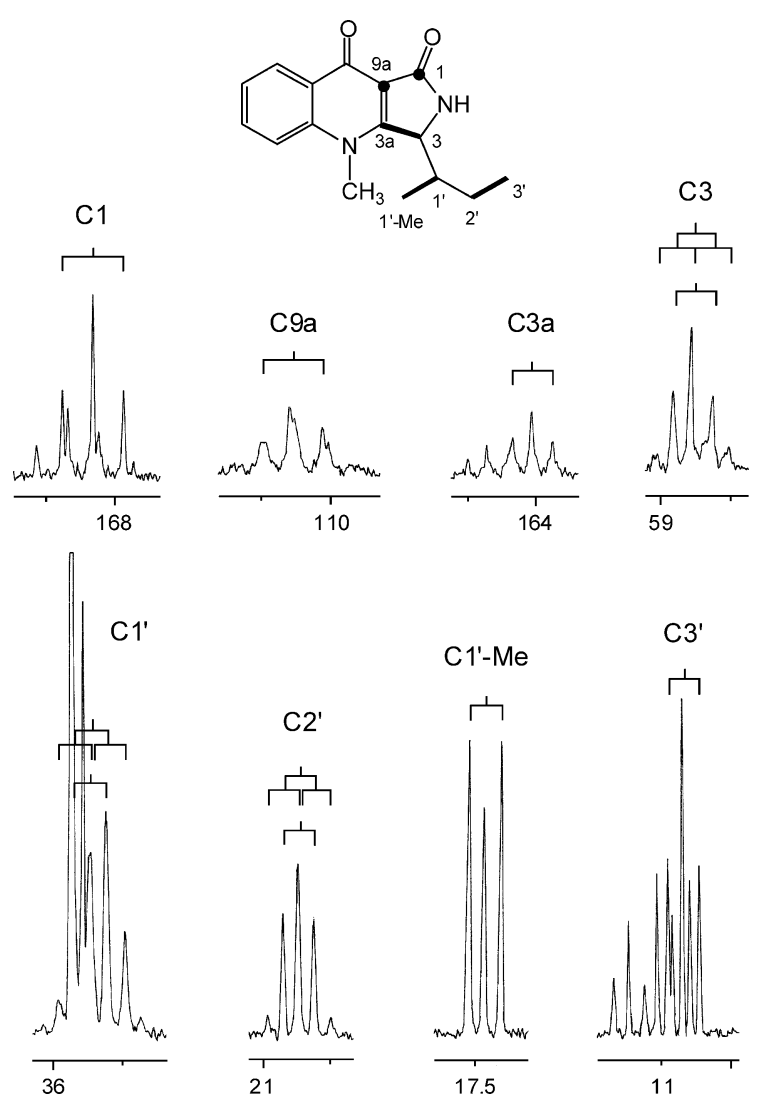

Fig. $3{ }^{13} \mathrm{C}$ NMR spectral patterns of the $\mathrm{C}-1, \mathrm{C}-1^{\prime}, \mathrm{C}-\mathbf{1}^{\prime}-$ $\mathrm{Me}, \mathrm{C}-2^{\prime}, \mathrm{C}-3, \mathrm{C}-3^{\prime}, \mathrm{C}-3 \mathrm{a}$, and C-9a carbons of $\mathbf{1}$ from the feeding of $\mathrm{D}-\left[\mathrm{U}^{-13} \mathrm{C}\right] \mathrm{glucose}$.

C-1' carbons were labeled randomly. However, the ratio of the observed C-3 signals was quite different from that estimated. Namely, the ratio of the singlet signal was low (24\%) and that of the doublet signal was high (47\%). The variance in the ratio of the isotopomers in the observed ${ }^{13} \mathrm{C}$ NMR signals compared with the theoretical consideration was also found at the C-3a, C-1', C-1'-Me, C-2', and C-3' carbons. These results demonstrated that ${ }^{13} \mathrm{C}$ was not randomly incorporated, but that a specific isotopomer was produced dominantly.

Isoleucine is biosynthesized via 2-aceto-2-hydroxybutyrate which is synthesized from a $\mathrm{C}_{2}$ unit of pyruvate, from which one carbon is lost by decarboxylation, and $\mathrm{C}_{4}$ unit of 2-ketobutyrate. In the conversion process to isoleucine, the bond derived from the $\mathrm{C}_{2}$ unit is not cleaved and subsequently constitutes the $\mathrm{C}_{\beta}$ and $\mathrm{C}_{\gamma}-\mathrm{CH}_{3}$ in isoleucine molecule. Because a pyruvate molecule is synthesized from a glucose molecule, the block of $\mathrm{C}_{\beta}$ and $\mathrm{C}_{\gamma}-\mathrm{CH}_{3}$ should be labeled by ${ }^{13} \mathrm{C}$ simultaneously or not labeled at all in an isoleucine molecule. In the same manner, the simultaneously labeled blocks derived from a single
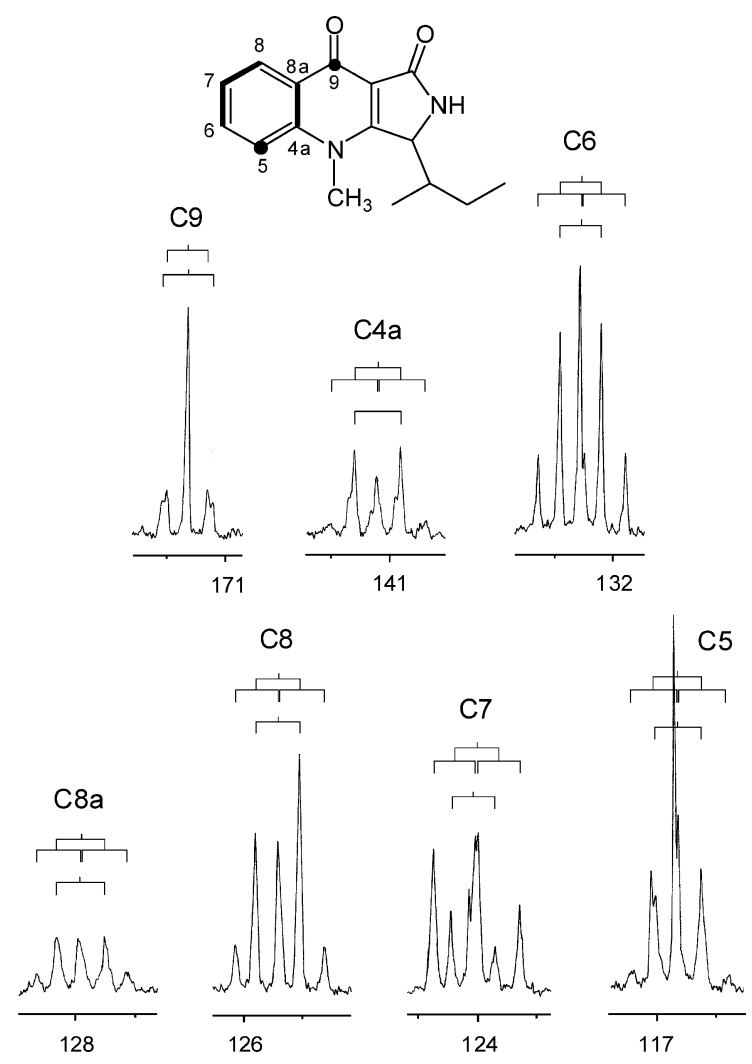

Fig. $4{ }^{13} \mathrm{C}$ NMR spectral patterns of the C-4a, C-5, C-6, C7, C-8, C-8a, and C-9 carbons derived from D- $\left[U_{-}{ }^{13} \mathrm{C}\right] \mathrm{glucose}$.

glucose molecule should be found at $\mathrm{C}_{\alpha}-\mathrm{C}_{\mathrm{co}}$ and $\mathrm{C}_{\gamma}-\mathrm{CH}_{2}-$ $\mathrm{C}_{\delta}$. The signal intensity ratios of $\mathbf{1}$ obtained by the feeding of D- $\left[U_{-}{ }^{13} \mathrm{C}\right]$ glucose at C-3a, C-3, C-1 $1^{\prime}, \mathrm{C}-1^{\prime}-\mathrm{Me}, \mathrm{C}-2^{\prime}$, and $\mathrm{C}-3^{\prime}$ showed good agreement with the labeling pattern of isoleucine. The high intensities of the doublet signals of these carbons indicate that the incorporations of ${ }^{13} \mathrm{C}$ atoms occurred from a single unit of this building block, not randomly. This result directly shows that the partial structure constructed by these carbons was derived from isoleucine. This finding was also supported by the direct incorporation of DL- $\left[1-{ }^{13} \mathrm{C}\right]$ isoleucine which labeled C-3a specifically (Table 2).

Figure 4 shows the ${ }^{13} \mathrm{C}$ NMR spectral patterns of the carbons at C-9, C-4a, C-6, C-8a, C-8, C-7, and C-5 of $\mathbf{1}$ from the feeding of $\mathrm{D}-\left[\mathrm{U}_{-}{ }^{13} \mathrm{C}\right]$ glucose. As shown in Fig. 4, the doublet signals at C- 6 and C-8, and the double doublet signal at C-7 are extremely intense. For the C-5 resonance, however, the ratio of the singlet signal is much higher compared with those of C-6, C-7, and C-8. This means that the $\mathrm{C}-6, \mathrm{C}-7$, and $\mathrm{C}-8$ carbons originated from a single, contiguous $\mathrm{C}_{3}$ unit derived from $\mathrm{D}-\left[U_{-}{ }^{13} \mathrm{C}\right]$ glucose, whereas the $\mathrm{C}-5$ carbon originated from a different moiety.

In the first step of aromatic ring formation, shikimic acid 


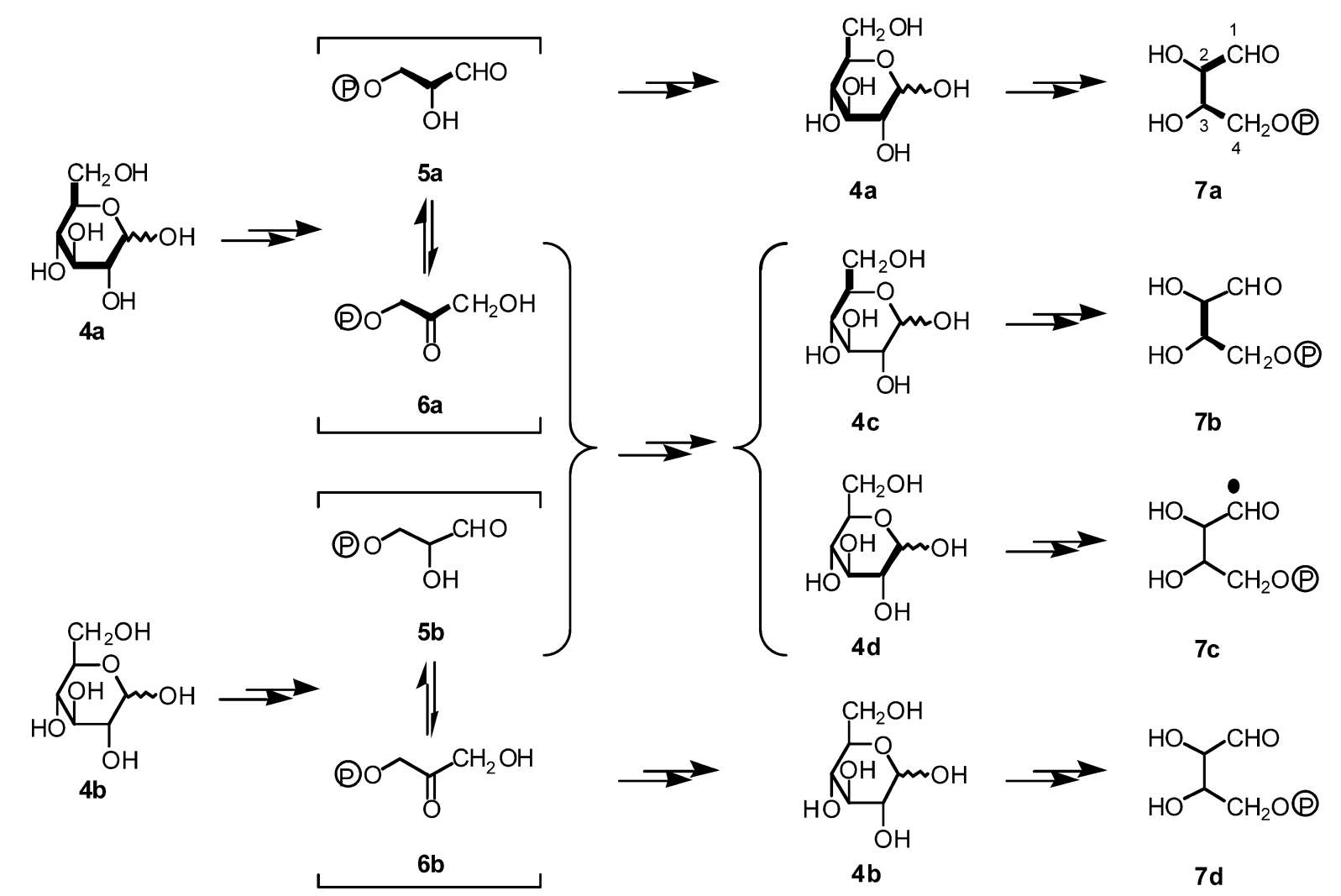

Fig. 5 The four isotopomers $(\mathbf{7 a}, \mathbf{7 b}, \mathbf{7 c}$, and $\mathbf{7 d})$ of erythrose 4-phosphate formed by feeding a mixture of $D-\left[U-{ }^{13} C\right] g l u c o s e(\mathbf{4 a})$ and non-labeled glucose $(\mathbf{4 b})$.

is formed from erythrose 4-phosphate (7) and phosphoenol pyruvate. Erythrose 4-phosphate is constructed from a $\mathrm{C}_{4}$ unit via the pentose-cycle (Fig. 5) through loss of a $\mathrm{C}_{2}$ unit from a fructose 6-phosphate molecule, which is derived from glucose. Consequently, by feeding a mixture of nonlabeled and $\mathrm{D}-\left[U_{-}{ }^{13} \mathrm{C}\right]$ glucoses, the $\mathrm{C}_{4}$ unit of erythrose 4phosphate either must have all carbons labeled (7a) or nonlabeled (7d). On the other hand, glucose is also metabolized into glyceraldehydes 3-phosphate (5) and dihydroxyacetone phosphate (6). Thus, if non-labeled glucose and $\mathrm{D}-\left[U_{-}{ }^{13} \mathrm{C}\right]$ glucose are metabolized according to this scheme, two kinds of $\mathrm{C}_{3}$ units described above are produced: i.e. one all labeled (5a and $\mathbf{6 a}$ ) and the other all non-labeled (5b and $\mathbf{6 b}) \mathrm{C}_{3}$ units.

These two $\mathrm{C}_{3}$ units (5 and 6) are used to produce fructose 6-phosphate and then glucose by catabolism (retrobiosynthesis) [19 21]. In the catabolic process to synthesize glucose, all of the labeled (5a and $\mathbf{6 a}$ ) and nonlabeled (5b and $\mathbf{6 b}) \mathrm{C}_{3}$ units must be used as sources randomly. As a result, four kinds of isotopomers (4a, $\mathbf{4 b}$, $\mathbf{4 c}$, and $4 \mathbf{d}$ ) of glucose are formed and are used in the biosynthesis of erythrose 4-phosphate to produce the four isotopomers (7a, $7 \mathbf{b}, \mathbf{7 c}$, and $\mathbf{7 d}$ ), as shown in Fig. 5.
These considerations are in agreement with the experimental results obtained by feeding $\mathrm{D}-\left[U_{-}{ }^{13} \mathrm{C}\right]$ glucose in the biosynthesis of quinolactacins. If there is no retrobiosynthesis, the $\mathrm{C}_{4}$ unit of $\mathrm{C}-5, \mathrm{C}-6, \mathrm{C}-7$, and $\mathrm{C} 8$ should be either all labeled simultaneously or not be labeled at all. As a result, the double doublet at C-6 should be more intense, like that of C-7. The ratio of the doublet for $\mathrm{C}-5$ should be high, due to the spin-spin coupling to C-6. However, the ${ }^{13} \mathrm{C}$ NMR signals observed were quite different from these expectations. It is therefore reasonable to suppose that the $\mathrm{D}-\left[\mathrm{U}_{-}{ }^{13} \mathrm{C}\right]$ glucose fed is metabolized into glyceraldehydes 3-phosphate and dihydroxyacetone phosphate and that glucose is reproduced from these $\mathrm{C}_{3}$ units. Subsequently, these isotopomers of glucose were metabolized to the labeled erythrose 4-phosphates and incorporated into C-5, C-6, C-7, and C-8 in 1. In addition, it was clarified that the aldehyde carbon of erythrose 4phosphate corresponded to the $\mathrm{C}-5$ position of $\mathbf{1}$ through an analysis of the labeling pattern (Fig. 2).

In general, anthranilic acid is the biosynthetic precursor of an aromatic moiety when it is formed via the shikimate pathway. However, as shown in Table 2, it was found that the carbonyl carbon of anthranilic acid was not 


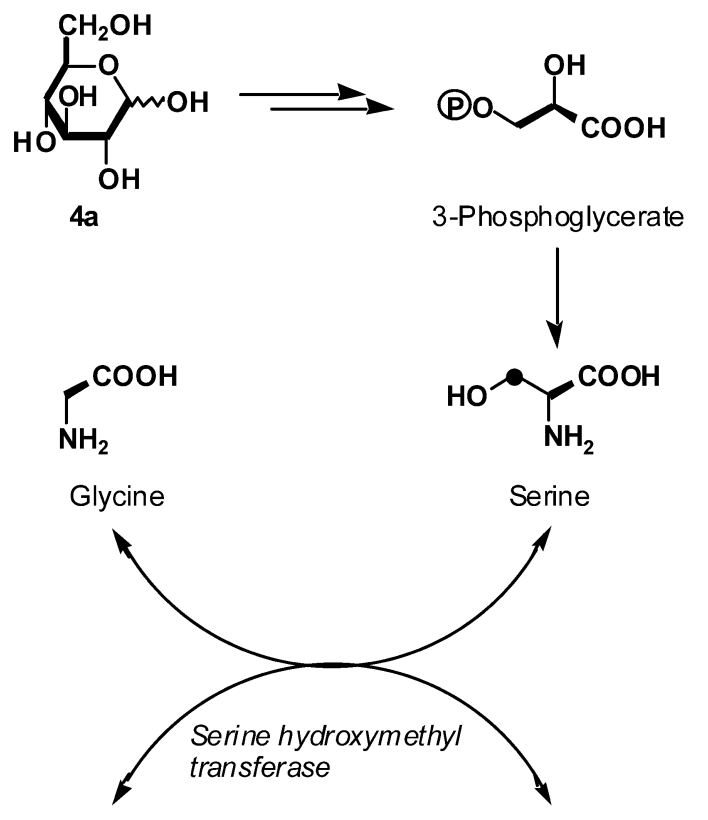

$5,6,7,8$-Tetrahydrofolate (THF)

5,10-Methylene-THF

Fig. 6 The formation of ${ }^{13} \mathrm{C}$ labeled tryptophan via serineglycine interconversion by serine hydroxymethyltransferase from D- $\left[U_{-}^{13} \mathrm{C}\right]$ glucose. incorporated into 1 . On the other hand, when $\mathrm{D}-[U-$ ${ }^{13} \mathrm{C}$ glucose was fed, the ratio of the singlet signal of the $\mathrm{C}$ 9 position in the ${ }^{13} \mathrm{C}$ NMR spectrum of $\mathbf{1}$ was as high as $62 \%$ (Table 3). Two kinds of doublet satellite signals for the C-9 signal were observed, due to the coupling between C-9 and C-8a, and C-9 and C-9a, respectively (Fig. 4). Because no hydrogen is attached to the $\mathrm{C}-9$ position, the ${ }^{13} \mathrm{C}$ enrichment ratio could not be estimated directly. If the ${ }^{13} \mathrm{C}$ enrichment ratio at the $\mathrm{C}-9$ position is considered to be the same as that of the aromatic ring (26\%), and each portion is randomly labeled, the ratio of singlet: doublet: double doublet signal is calculated to be $55: 38: 7$. This estimate is in good agreement with the experimental results shown in Table $2(62: 38: \sim 0)$. This means that the incorporation of the carbons at C-8a and C-9 occurred independently. Anthranilic acid is biosynthesized from erythrose 4-phosphate and phosphoenol pyruvate. Because the carboxyl carbon is derived a pyruvate moiety, if anthranilic acid is incorporated into $\mathbf{1}$ intact, the intensity ratio of the doublet signal at C-9 should be relatively high. The observations described above and the estimated signal intensity ratios indicated that the C-9 carbon was not derived from anthranilic acid.

Table $3{ }^{13} \mathrm{C}$ NMR resonance data of quinolactacin $\mathrm{A}$ obtained from the feeding experiment of D-[U- $\left.{ }^{13} \mathrm{C}\right] g$ lucose

\begin{tabular}{|c|c|c|c|c|c|c|}
\hline \multirow{2}{*}{ Position } & \multirow{2}{*}{$\delta(\mathrm{ppm})$} & \multirow{2}{*}{$\begin{array}{c}{ }^{13} \mathrm{C} \text { abundance }{ }^{a} \\
(\%)\end{array}$} & \multicolumn{3}{|c|}{ Signal intensity ratio ${ }^{b}(\%)$} & \multirow{2}{*}{$\mathrm{JcC}^{\mathrm{C}}(\mathrm{Hz})$} \\
\hline & & & Singlet & Doublet & Double doublet & \\
\hline 1 & 168.3 & & 57 & 43 & - & $J_{1-9 a}=66.2$ \\
\hline 3 & 58.9 & 12 & 24 & 47 & 29 & $J_{3-3 a}=44.1$ \\
\hline $3 a$ & 164.0 & & 43 & 57 & $\sim 0$ & \\
\hline $4 N-\mathrm{Me}$ & 36.0 & 15 & 100 & - & - & \\
\hline $4 a$ & 141.2 & & 25 & 70 & 5 & $J_{4-8 a}=60.4$ \\
\hline 5 & 117.0 & 23 & 40 & 47 & 13 & $J_{5-6}=57.3$ \\
\hline 6 & 132.4 & 23 & 19 & 49 & 32 & $J_{6-7}=52.9$ \\
\hline 7 & 124.2 & 30 & 9 & 19 & 72 & $J_{7-8}=57.3$ \\
\hline 8 & 125.8 & 27 & 12 & 61 & 27 & $J_{8-8 \mathrm{a}}=61.7$ \\
\hline $8 a$ & 128.0 & & 16 & 54 & 30 & $J_{8 a-9}=63.6^{d}$ \\
\hline 9 & 171.5 & & 62 & 38 & 0 & $J_{9-9 a}=52.8^{d}$ \\
\hline $9 a$ & 110.3 & & 38 & 50 & 12 & \\
\hline $1^{\prime}$ & 35.7 & 20 & 30 & 56 & 14 & $J_{1-1^{\prime} \mathrm{Me}}=35.3$ \\
\hline $1^{\prime}-\mathrm{Me}$ & 17.5 & 26 & 28 & 72 & - & \\
\hline $2^{\prime}$ & 20.8 & 12 & 34 & 49 & 17 & $J_{2^{\prime}-3^{\prime}}=35.3$ \\
\hline $3^{\prime}$ & 11.4 & 9 & 44 & 56 & - & \\
\hline
\end{tabular}

${ }^{a}$ The ${ }^{13} \mathrm{C}$ abundances of the respective carbons were obtained from the satellite signals in the ${ }^{1} \mathrm{H}$ NMR spectrum.

${ }^{b}$ The ratios were calculated from the integration of satellite signals in the ${ }^{13} \mathrm{C}$ NMR spectrum. The intensities of the four double doublet signals were assumed to be the same.

${ }^{c}$ Values are listed only for clearly observed satellite signals.

${ }^{d}$ These are assigned tentatively. 
It is considered that $\mathrm{C}-4 \mathrm{a}$ and $\mathrm{C}-8 \mathrm{a}$ are derived from the same biosynthetic unit, because of the high ratio of these doublet satellite signals in the ${ }^{13} \mathrm{C}$ NMR spectrum of $\mathbf{1}$ (Table 3 and Fig. 4). On the other hand, the ratio of the double doublet signal at $\mathrm{C}-8 \mathrm{a}$ is low. These results also agree with the notion that $\mathrm{C}-9$ is derived from another unit. It is estimated that the carboxyl carbon of an anthranilic acid unit attributed to C-9 of $\mathbf{1}$ was first eliminated by decarboxylation during biosynthesis, and that a carbon was added subsequently to this position from a different biosynthetic unit (Fig. 2).

In addition, the ${ }^{13} \mathrm{C}$ NMR signal of the $\mathrm{C}-9$ a position showed a ratio in which a singlet signal was slightly higher than the other doublet dominant positions. This also indicates that the carbon attributed to C-9a was derived from a different biosynthetic unit than that of C-9, and it was concluded that each of the carbons C-8a, C-9, and C$9 \mathrm{a}$ originated from different biosynthetic units.

From the observations described above, the biosynthetic pathway of 1 was concluded to be as shown in Fig. 2. The labeling pattern of C-5, C-6, C-7, and C-8 shows that this $\mathrm{C}_{4}$ unit $\left(\mathrm{C}_{1}+\mathrm{C}_{3}\right)$ was derived from shikimic acid. Anthranilic acid is also biosynthesized via shikimate pathway, however, in the biosynthesis of $\mathbf{1}$, an anthranilic acid unit is not incorporated intact into $\mathbf{1}$. Instead, it apparently combines with a ribose moiety to form an indole skeleton. During this process, the carbon of the carboxylic acid moiety of anthranilic acid is eliminated by decarboxylation.

The indole is transformed into tryptophan by the condensation of serine with the aid of tryptophan synthetase. The serine was biosynthesized from a $\mathrm{C}_{3}$ unit derived from a glucose unit, and retains the labeling pattern [22 24]. However, the hydroxy methyl carbon of serine is actively exchanged by the action of serine hydroxymethyltransferase to form a glycine molecule; glycine can acquire a hydroxy methyl moiety to form serine. As a result, the hydroxy methyl carbon of serine is labeled at random. Thus, a serine molecule formed by the feeding of D- $\left[U-{ }^{13} \mathrm{C}\right]$ glucose possesses ${ }^{13} \mathrm{C}-{ }^{13} \mathrm{C}$ and single ${ }^{13} \mathrm{C}$ units from the serine-glycine interconversion, and this unit is incorporated into tryptophan. (Figs. 2 and 6). Consequently, the origin of the $\mathrm{C}_{\beta}$ methylene carbon of tryptophan differs from that of $\mathrm{C}_{\alpha}$, and the $\mathrm{C}_{\beta}$ and $\mathrm{C}_{\gamma}$ carbons of kynureine are derived from other biosynthetic units, as shown in Fig. 2.

When tryptophan is transformed into kynurenine, a cleavage occurs between the $\mathrm{C}_{\gamma}$ and $\mathrm{C}_{\delta}$ carbons, followed by $N$-deformylation (loss of $\mathrm{C}_{\delta}$ ). Kynurenine is then proposed to combine with an isoleucine molecule and cyclized to form a quinolone ring [intermediate (8)], followed by oxidative decarboxylation and lactam formation. Consequently, the consecutive carbons at C-1, C-9a, C-9, and $\mathrm{C}-8 \mathrm{a}$ of $\mathbf{1}$ originate from different biosynthetic units. A methyl moiety is postulated to be incorporated at the $N-4$ position from methionine and quinolactacin A (1) is formed.

The experimental results described above are good demonstration that detailed ${ }^{13} \mathrm{C}$ NMR spectral analysis of the compounds obtained by feeding a mixture of non-labeled glucose and $\mathrm{D}-\left[U_{-}{ }^{13} \mathrm{C}\right]$ glucose can afford an accurate biosynthetic pathway for metabolites and determination of the origin of each carbon atom therein.

Acknowledgements We appreciate the assistance of Professor Geoffrey A. Cordell, University of Illinois at Chicago, for reviewing the manuscript prior to submission.

\section{References}

1. Roberts DW. Toxins of entomopathogenic fungi. In Microbial Control of Pests and Plant Diseases 1970 1980. Burges HD. (Ed.): Academic Press, London, New York, pp. 441-464 (1981)

2. Hajek AE, St. Leger RJ. Interractions between fungal pathogens and insect hosts. Annu Rev Entomol 39: 293-322 (1994)

3. Hamill RL, Higgens CE, Boaz HE, Gorman M. The structure of beauvericin, a new depsipeptide antibiotic toxic to Artemia salina. Tetrahedron Lett 10: 4255-4258 (1969)

4. Suzuki A, Kanaoka M, Isogai A, Murakoshi S, Ichinoe M, Tamura, S. Bassianolide a new insecticidal cyclodepsipeptide from Beauveria bassiana. Tetrahedron Lett 18: 2167-2170 (1977)

5. Fujita $\mathrm{T}$, Inoue $\mathrm{K}$, Yamamoto $\mathrm{S}$, Ikumoto $\mathrm{T}$, Sasaki $\mathrm{S}$, Toyama R, Chiba K, Hoshino Y, Okumoto T. Fungal metabolites. Part 11. A potent immunosuppressive activity found in Isaria sinclairii metabolite. J Antibiot 47: 208-215 (1994)

6. Iijima M, Masuda T, Nakamura H, Naganawa H, Kurasawa S, Okami Y, Ishizuka M, Takeuchi T, Iitaka Y. Metacytofilin, a novel immunomodulator produced by Metarhrizium sp. TA2759. J Antibiot 45: 1553-1556 (1992)

7. Mochizuki K, Ohomori K, Tamura H, Shizuri Y, Nishiyama S, Miyoshi E, Yamamura S. The structures of bioactive cyclodepsipeptides, beauveriolides I and II, metabolites of entomopathogenic fungi Besuveria sp. Bull Chem Soc Jpn 66: 3041-3046 (1993)

8. Takahashi S, Kakinuma N, Uchida K, Hashimoto R, Yanagisawa T, Nakagawa A. Pyridovericin and pyridomacrolidin: novel metabolites from entomopathogenic fungi, Beauveria bassiana. J Antibiot 51: 596-598 (1998)

9. Takahashi S, Uchida K, Kakinuma N, Hashimoto R, Yanagisawa T, Nakagawa A. The structures of pyridovericin 
and pyridomacrolidin, new metabolites from the entomopathogenic fungus, Beauveria bassiana. J Antibiot 51: 1051-1054 (1998)

10. Kakinuma N, Iwai H, Takahashi S, Hamano K, Yanagisawa T, Nagai K, Tanaka K, Suzuki K, Kirikae F, Kirikae T, Nakagawa A. Quinolactacins A, B and C: novel quinolone compounds from Penicillium sp. EPF-6. I. Taxonomy, production, isolation and biological properties. J Antibiot 53: 1247-1251 (2000)

11. Takahashi S, Kakinuma N, Iwai H, Yanagisawa T, Nagai K, Suzuki K, Tokunaga T, Nakagawa A. Quinolactacins A, B and $\mathrm{C}$ : novel quinolone compounds from Penicillium sp. EPF-6. II. Physico-chemical properties and structure elucidation. J Antibiot 53: 1252-1256 (2000)

12. Kim WG, Song HK, Yoo ID. Quinolactacins A1 and A2, new acetylcholinesterase inhibitors from Penicillium citrinum. J Antibiot 54: 831-835 (2001)

13. Tatsuta K, Misawa H, Chikauchi K. Biomimetic total synthesis of quinolactacin $\mathrm{B}$, TNF production inhibitor, and its analogs. J Antibiot 54: 109-112 (2001)

14. Newman MS. $\alpha$-Naphthonitrile. Organic Syntheses Coll Vol III: $631-633$ (1955)

15. Ito T, Watanabe K. Studies of organic catalytic reactions. VI. The function of pyridine and copper in the Rosenmund-von Braun reaction. Bull Chem Soc Jpn 41: 419-423 (1968)

16. Nakagawa A, Takahashi S, Uchida K, Matsuzaki K, Ōmura S, Nakamura A, Kurihara N, Nakamatsu T, Miyake Y, Take K, Kainosho M. Biosynthesis of lactacystin. Origin of the carbons and stereospecific NMR assignment of the two diastereotopic methyl groups. Tetrahedron Lett 35: 5009-5012 (1994)
17. Takahashi S, Uchida K, Nakagawa A, Miyake Y, Kainosho M, Matsuzaki K, Ōmura S. Biosynthesis of lactacystin. J Antibiot 48: 1015-1020 (1995)

18. Gupta RN, Hemscheidt T, Sayer BG, Spenser ID. Biosynthesis of vitamin $\mathrm{B}_{6}$ in yeast: incorporation pattern of glucose. J Am Chem Soc 123: 11353-11359 (2001)

19. Werner I, Bacher A, Eisenreich W. Retrobiosynthetic NMR studies with ${ }^{13} \mathrm{C}$-labeled glucose. Formation of gallic acid in plants and fungi. J Biol Chem 272: 25474-25482 (1997)

20. Eisenreich W, Bacher A, Berry A, Bretzel W, Hümbelin M, Lopez-Ulibarri R, Mayer AF, Yeliseev A. Biosynthesis of zeaxanthin via mevalonate in Paracoccus species strain PTA-3335. A product-based retrobiosynthetic study. J Org Chem 67: 871-875 (2002)

21. Moore BS, Walker K, Tornus I, Handa S, Poralla K, Floss HG. Biosynthetic studies of $\omega$-cycloheptyl fatty acids in Alicyclobacillus cycloheptanicus. Formation of cycloheptanecarboxylic acid from phenylacetic acid. J Org Chem 62: 2173-2185 (1997)

22. Aberhart DJ, Russell DJ. Steric course of ketopantoate hydroxymethyltransferase in E. coli. J Am Chem Soc 106: 4902-4906 (1984)

23. Aberhart DJ, Russell DJ. Steric course of $N^{5}, N^{10}$ methylenetetrahydrofolate formation from glycine by the glycine cleavage system in E. coli. J Am Chem Soc 106: 4907-4910 (1984)

24. Cowin GJ, Willgoss DA, Bartley J, Endre ZH. Serine isotopomer analysis by ${ }^{13} \mathrm{C}-\mathrm{NMR}$ defines glycine-serine interconversion in situ in the renal proximal tubule. Biochim Biophys Acta 1310: 32-40 (1996) 